\title{
The Perception of Athletes on the Factors Affecting to Coach Leadership Behavior Styles: An Empirical Study on Leadership Styles Exhibited by the Coaches of State Universities in Western Province - Sri Lanka
}

\author{
${ }^{1}$ H. P. N. Perera and ${ }^{2}$ M. D. Pushpakumari \\ ${ }^{1}$ Faculty of Applied Sciences, Sports Science and Management Degree Programme, University of Sri \\ Jayewardenepura, Sri Lanka \\ ${ }^{2}$ Department of Business Administration, Faculty of Management Studies and Commerce, \\ University of Sri Jayewardenepura, Sri Lanka
}

\begin{abstract}
Leadership in sports has been studied mostly in terms of coach-leadership. Coach leadership behavior has an impact on players' performance. The purpose of this study is to understand the impact of situational, leader, and team member characteristics on coach leadership behavior styles in sports in state universities in Western Province, Sri Lanka. This study was conducted during the inter-university games held in 2014 considering the events of basketball, netball, volleyball, and Elle. Two hundred and ninety one athletes from Western Province state universities participated in this study. Gender, age, locus of control, and level of education and training variables were considered under coach characteristics. Nature of the sport, level of competition, and previous success and/or failure records were considered as situational factors which affect coach behaviors. Team member characteristics taken into consideration were gender, age, culture, and experiences. Data were collected through a standard questionnaire which was derived from the revised leadership scale for sports. Mean calculations was used as a parametric test to derive the influence of situational characteristics of the coach, leader and team member characteristics on coach leadership behavior. Statistical calculations were done using SPSS version 16.0.It was found that coaches carry out more training and instruction behavior in relation to females than males. Further, compared to females, males urge a higher influence on coaches to follow an autocratic behavior. Results further revealed that when the experiences of the athletes are less, they prefer their coaches to be more democratic. Additionally, it is found that the coaches carry out more situational consideration behavior when the level of competition is high. It can be concluded that the situational, leader, and team member characteristics have a moderate influence on coach leadership behavior. The findings of the study may influence researchers to engage in further research and also will be helpful for coaches to make decisions on athletes.
\end{abstract}

KEYWORDS: Coach leadership, team-member characteristics, situational characteristics, leader characteristics, athletes

Corresponding author: H.P.N. Perera, Email: piumiri@yahoo.com 


\section{INTRODUCTION}

Sports, undoubtedly, are important to a country in many ways. Sports can be used as a tool to make a better world (The Olympic Museum, 2011). The Olympic Museum (2011) categorized the main focusing areas which preserve advantages of sports and related activities as human dimension, political dimension and societal dimension.

Sri Lanka was suffering from a civil war for more than thirty years and the government had prevailed war in year 2009. Central Bank Annual Report published in 2013 mentioned that "with the continuity of the peaceful environment in the country, expenditure on recreational, cultural and sporting activities has improved during 2013".

Although budget allocations are made, there arises a necessity of understanding the actual facts behind the hindering progress of sports. Sri Lanka has not been able to gain Olympic medals since 2000. It is not only the athletes but also the coaches have the responsibility for the better performance of the athletes.

Barrow (1977) defined leadership as "the behavioral process of influencing individuals and groups towards set goals". Most coaches use different leadership styles at one time or another for different situations.

Some styles are more suitable in certain situations than others. For this reason, it is beneficial for the coach to know which leadership behaviors will facilitate performance. Therefore there arises a necessity to identify which leadership behaviors should be demonstrated by the coaches and the factors affecting to such leadership behaviors.

This research is mainly focused on finding out the impact of situational, leader and team member characteristics on coach leadership behavior.

\section{LITERATURE REVIEW}

Multidimensional model of leadership (Chelladurai and Saleh, 1980; Chelladurai and Carron, 1978) is one of the main models developed during last few decades which cited equal emphasis on the role of both the coach and the athlete. This model to show the interactions based upon the characteristics team members and leaders.

Chelladurai and Saleh (1980) developed a questionnaire in order to verify the adequacy of the Multidimensional Model of Leadership developed by Chelladurai and Carron (1978) namely Leadership Scale for Sports (LSS). This scale has been used by researchers to measure the athletes' perception of their coaches' leadership behaviors/styles according to five dimensions, namely training and instruction, autocratic behavior, democratic behavior, social support behavior, and positive feedback behavior which is elaborated in Table 1 .

Table 1. Leadership scale for sports

\begin{tabular}{|l|l|}
\hline \multicolumn{1}{|c|}{ Subscale } & \multicolumn{1}{c|}{ Description } \\
\hline $\begin{array}{l}\text { Training } \\
\text { and }\end{array}$ & $\begin{array}{l}\text { The coach helps athletes to reach their } \\
\text { maximum physical potential by } \\
\text { providing them training and technical } \\
\text { support. He or she is also expected to } \\
\text { instruct them in how to acquire the } \\
\text { necessary skills and to teach them the } \\
\text { techniques and the tactics of the sports. }\end{array}$ \\
\hline $\begin{array}{l}\text { Autocratic } \\
\text { Style }\end{array}$ & $\begin{array}{l}\text { This indicates the extent to which a } \\
\text { coach keeps apart from the athletes and } \\
\text { stresses his or her authority in dealing } \\
\text { with them. }\end{array}$ \\
\hline $\begin{array}{l}\text { Democratic } \\
\text { Style }\end{array}$ & $\begin{array}{l}\text { It reflects the extent to which the coach } \\
\text { permits participation of the athletes in } \\
\text { decision making. }\end{array}$ \\
\hline $\begin{array}{l}\text { Social } \\
\text { Support }\end{array}$ & $\begin{array}{l}\text { This refers to the extent to which the } \\
\text { coach is involved in satisfying the } \\
\text { interpersonal needs of the athletes. }\end{array}$ \\
\hline $\begin{array}{l}\text { Positive } \\
\text { feedback }\end{array}$ & $\begin{array}{l}\text { Leadership behavior which is } \\
\text { visualized by praise and reinforcement } \\
\text { in respect to athletes' performance. }\end{array}$ \\
\hline
\end{tabular}

Source: Manual for leadership scale for sports by

P. Chelladurai (1980) 
The Revised Leadership Scale for Sports (RLSS) developed by Zhang, Jensen and Mann (1997) emphasizes another coach leadership behavior other than situational consideration behavior.

Smoll and Smith (1989) developed a model of adult leadership behaviors in sports which illustrates factors that affect coach behavior. Those variables are coach individual difference variables, player individual difference variables, and situational factors.

Chelladurai (2007), in multidimensional model of leadership has considered leader, member and situational characteristics as the factors that affect coach behavior. The factors identified by Smoll and Smith (1984) and others which affect coach leadership behaviors are described in the following sections.

\subsection{Leader / coach characteristics}

One of the coach individual difference variables identified by Smoll and smith (1984) is the sex/gender of the coach. Rintaugu and Bailasha (2011) found that female coaches had higher mean scores than male, in all five dimensions of coach leadership irrespective of democratic behavior.

Chelladurai and Carron (1983) found that preference for autocratic coaching behavior increases with the age athletic maturity. Smith and Smoll (1989) stated that coaches as adult leaders not only have their own goals and related instrumentalities, but they also have understanding of basic motives of the youngsters who play for them. Terry (1984) found no age differences in the five dimensions of coach leadership scale.

Locus of control can be divided into internal locus of control and external locus of control. Individuals with internal locus of control are called internals who believe that they have control over their destinies, Rotter (1966).
Level of education and training of the coach is another factor identified under leader characteristics. Based on results of a study done by Rintaugu and Bailasha (2011) coachleadership behavior has been defined by level of education, indicating that coaches with university level of education had higher mean scores across all the five dimensions of coachleadership behaviors.

\subsection{Team member (Athlete)characteristics}

The model developed by Smoll and Smith (1984) identified variables such as age, sex, and so forth as player individual difference variables that affect coach leadership behavior.

Terry and Howe (1984) showed that preference scores of the male athletes were significantly higher than female athletes for autocratic behavior only. Based on responses of athletes, Chelladurai and Arnott (1985) found that coaches allowed the female athletes to participate in decision-making process more significantly than with male athletes.

Chelladurai and Saleh (1978), Terry (1984) Terry and Howe (1984) and Lim (1995), have concluded that athletes in team sports prefer more training behavior and less democratic behavior, and social support behavior than individual athletes. According to Riemer and Toon (2001), stated that athlete's gender was significant in the case of autocratic behavior and positive feedback behavior. Chelladurai and Saleh (1980) also reported similar findings.

Age of the athlete is an important variable considered by the researchers under team member characteristics. Terry (1984) pointed out that no significant curvilinear relationship persists between age and coaching preference.

Nationality and culture in which they are from, is one of the variables considered by the researchers in relation to team member characteristics. Terry (1984) found that no 
significant differences in preferred coaching behavior attributable to the age or nationally of the athlete.

\subsection{Situational characteristics of a coach}

The model developed by Smoll and Smith (1984) identified nature of the sport, level of competition, and previous success/failure records as situational factors which affect coach behaviors.

Chelladurai and Saleh (1978) and Terry and Howe (1984) found that athletes in team sports prefer more training behavior and less democratic behavior, and social support behavior. Smith et al. (1983) found that the nature of the sport influence behavior patterns. Level of completion is another factor considered by the researchers under this category. Smoll and Smith (1989) stated that the level of competition, and previous success and failure of games are not difficult to code under situational factors.

\section{RESEARCH METHODOLOGY}

Based on the literature the following conceptualized model (Figure 1) was developed.

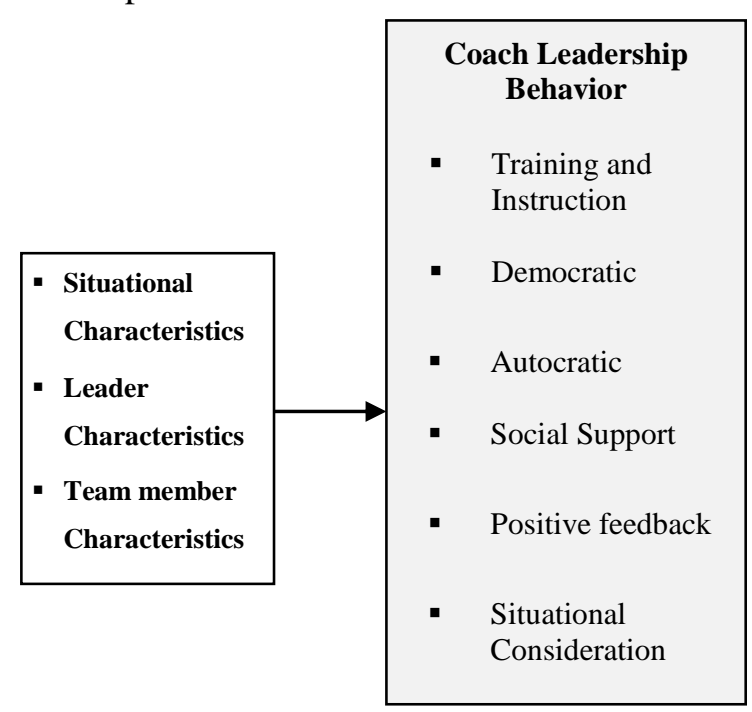

Figure 1. Conceptualized model

\subsection{Population and Sample}

The total population under consideration was 480 male and female athletes from state universities in Western Province, whom are engaging in the sports events of Basketball, Hockey, Volleyball, and Elle. The sample consisted of two hundred and ninety one $(n=291)$ athletes. It is intended to consider the whole population but operational responses were only 291.

\subsection{Data Collection}

Other than the primary sources, a questionnaire was used which derived from RLSS. The reliability of the questionnaire was evaluated using the Cronbach's Alpha test (Cronbach's Alpha value of 0.80 ) which is higher than cutoff value suggested by Nunnally (1978).

\section{RESULTS AND DISCUSSION}

Mean scores are considered when analyzing data. Out of the 32 coaches, thirty coaches are male (93.75\%) and only two (6.28\%) are female coaches. The mean values depict in the table 02 male and female coaches characterizes the leadership styles of situational, feedback, democratic and training but not autocratic behavior.

The results of the study are consistent with Riemer and Toon (2001), in the case of social support behavior. The results of the study of Rintaugu and Bailasha (2011) showed that female coaches have higher mean scores than their male counterparts in all five dimensions except for democratic behavior which is partially consistent with this study.

According to the mean values depicts in table 02, athletes perceive more on coach leadership styles other than the autocratic behavior irrespective of coach's age level. This is partially consistent with Rintaugu and Bailasha (2011) and Terry (1984). 
Table 2. Leader characteristics

\begin{tabular}{|l|c|c|c|c|c|c|c|c|c|c|}
\hline \multirow{2}{*}{$\begin{array}{c}\text { Coach } \\
\text { Leadership } \\
\text { styles }\end{array}$} & \multicolumn{2}{|c|}{ Gender } & \multicolumn{4}{c|}{ Coach age } & \multicolumn{2}{c|}{$\begin{array}{c}\text { Locus of } \\
\text { control }\end{array}$} & \multicolumn{2}{c|}{$\begin{array}{c}\text { Coach explain } \\
\text { each player on } \\
\text { techniques }\end{array}$} \\
\cline { 2 - 11 } & Male & Female & Young & $\begin{array}{c}\text { Middle } \\
\text { age }\end{array}$ & $\begin{array}{c}\text { Young }+ \\
\text { Middle aged }\end{array}$ & Old & Yes & No & Yes & No \\
\hline Training & 3.79 & 4.00 & 4.32 & 3.84 & 4.08 & 3.62 & 4.16 & 3.85 & 3.99 & 4.20 \\
Democratic & 3.95 & 3.97 & 4.12 & 3.91 & 4.01 & 4.00 & 3.87 & 3.92 & 3.99 & 4.17 \\
Autocratic & 2.00 & 1.83 & 1.76 & 1.98 & 1.87 & 1.89 & 1.94 & 1.85 & 1.81 & 1.52 \\
Social & 3.11 & 3.10 & 3.24 & 3.06 & 3.15 & 3.14 & 3.07 & 3.32 & 3.27 & 3.38 \\
Feedback & 4.05 & 4.08 & 4.28 & 4.04 & 4.16 & 3.95 & 4.06 & 3.91 & 4.22 & 4.09 \\
Situational & 4.14 & 4.08 & 4.11 & 4.13 & 4.12 & 4.04 & 4.16 & 3.85 & 4.21 & 4.42 \\
\hline
\end{tabular}

Source: Survey data, 2014

Table 3. Team member characteristics

\begin{tabular}{|c|c|c|c|c|c|c|c|c|c|c|c|c|}
\hline \multirow{2}{*}{$\begin{array}{l}\text { Coach } \\
\text { Leader } \\
\text { Behavior }\end{array}$} & \multicolumn{2}{|c|}{ Gender. } & \multicolumn{4}{|c|}{ Age group. } & \multicolumn{3}{|c|}{$\begin{array}{c}\text { Culture in which they } \\
\text { are from } \\
\text { (Home Town) }\end{array}$} & \multicolumn{3}{|c|}{ Experience } \\
\hline & Male & Female & $\begin{array}{l}20-22 \\
\text { Years }\end{array}$ & $\begin{array}{l}23-25 \\
\text { years }\end{array}$ & $\begin{array}{l}26-28 \\
\text { years }\end{array}$ & \begin{tabular}{|c} 
Above \\
28 \\
years
\end{tabular} & Urban & Suburb & Rural & $\begin{array}{c}>1 \\
\text { year }\end{array}$ & $\begin{array}{c}1-5 \\
\text { years }\end{array}$ & $\begin{array}{c}<5 \\
\text { years }\end{array}$ \\
\hline Training & 3.79 & 4.00 & 3.99 & 3.93 & 3.42 & 0 & 3.84 & 3.88 & 3.93 & 4.10 & 3.87 & 3.82 \\
\hline Democratic & 3.95 & 3.98 & 3.92 & 3.97 & 4.03 & 0 & 4.07 & 3.96 & 3.87 & 3.99 & 3.83 & 4.16 \\
\hline Autocratic & 2.00 & 1.83 & 2.10 & 1.88 & 1.88 & 0 & 1.87 & 1.93 & 1.95 & 2.00 & 2.02 & 1.74 \\
\hline Social & 3.11 & 3.10 & 3.25 & 3.09 & 2.93 & 0 & 3.16 & 3.17 & 3.00 & 3.31 & 3.01 & 3.15 \\
\hline Feedback & 4.05 & 4.08 & 4.21 & 4.05 & 3.90 & 0 & 4.09 & 4.05 & 4.06 & 4.26 & 4.06 & 3.99 \\
\hline Situational & 4.14 & 4.08 & 4.22 & 4.10 & 3.99 & 0 & 4.18 & 4.05 & 4.12 & 4.18 & 4.07 & 4.15 \\
\hline
\end{tabular}

Source: Survey data, 2014

Table 4. Situational characteristics

\begin{tabular}{|c|c|c|c|c|c|c|c|c|}
\hline \multirow{2}{*}{$\begin{array}{c}\text { Coach } \\
\text { leader } \\
\text { behavior }\end{array}$} & \multicolumn{3}{|c|}{ Risk of getting injury } & \multirow{2}{*}{$\begin{array}{c}\text { Competition } \\
\text { among }\end{array}$} & \multicolumn{3}{|c|}{$\begin{array}{c}\text { Previous success reports of present } \\
\text { coach }\end{array}$} \\
\cline { 2 - 3 } \cline { 6 - 9 } & High & Moderate & Low & $\begin{array}{c}\text { universities } \\
\text { are high }\end{array}$ & Satisfied & $\begin{array}{c}\text { Not } \\
\text { satisfied }\end{array}$ & $\begin{array}{c}\text { Not } \\
\text { relevant }\end{array}$ & No idea \\
\hline Training & 3.72 & 3.91 & 4.05 & 3.89 & 4.18 & 2.84 & 3.6 & 3.98 \\
Democratic & 3.99 & 4.03 & 3.88 & 3.96 & 4.01 & 3.83 & 3.65 & 3.74 \\
Autocratic & 1.82 & 1.85 & 2.09 & 1.92 & 1.88 & 1.97 & 2.13 & 2.57 \\
Social & 3.02 & 3.34 & 3.02 & 3.10 & 3.2 & 2.71 & 3.16 & 3.52 \\
Feedback & 4.02 & 4.20 & 4.00 & 4.06 & 4.13 & 3.82 & 4.14 & 4.10 \\
Situational & 4.14 & 4.17 & 4.04 & 4.11 & 4.15 & 4.01 & 3.88 & 3.84 \\
\hline
\end{tabular}

Source: Survey data, 2014 
Further when the athletes perceive that their coach believes on his skills (internal locus of control), they perceive more training and instruction, positive feedback and situational consideration behavior, respectively.

Level of education and training of the coach could not be accessed since data are collected only from athletes.

"Coach explains each member on techniques" is a variable identified during the pilot survey and when he explains, athletes perceive more feedback and situational behavior and when he does not explain they perceive behaviors other than autocratic and social support behavior.

According table 03 coaches carry out more training and instruction behavior in relation to females than males and simultaneously male influence on coach to follow autocratic behavior.

In the context of gender, athlete gender has been tested across a wide range of team and individual sports Chelladurai and Arnott (1985), Chelladurai and Saleh (1978), Terry (1984) Terry and Howe (1984) and Lim (1995).

According to the study conducted by Riemer and Toon (2001) it has been stated that athlete's gender was significant in the case of autocratic behavior and positive feedback behavior which has elaborated as female athletes preferred more positive feedback behavior than did male counterparts and male athletes prefer more autocratic behavior than did females.

Terry (1984) showed that male athletes prefer more autocratic behavior than female athletes, which partially supported the research finding of Chelladurai and Saleh's (1978).

According to studies conducted by Smith et al. (1989) females perceived their coaches as giving more frequent reinforcement and encouragement, and less punishment and technical instruction than did the boys who rated their male coaches.

Accordingly it can be concluded that male prefer autocratic behavior than females which has been reported by Chelladurai and Saleh (1978) and Terry (1984).

Terry (1984) found that male athletes prefer significantly more social support behavior and significantly less democratic behavior than female athletes. Reimer and Toon (2001) pointed out from their study that neither gender in the present context actually preferred coaches to be autocratic. The results of this study are partially consistent with the findings of above studies and not with Reimer and Toon (2001).

When the age level of athletes is less, coaches practice more training and instruction, autocratic, social support, positive feedback and situational consideration behavior. It is the opposite for democratic behavior where, when age level of the athlete increases, coaches follow a more democratic behavior.

Smith and Smoll (1989) demonstrated the young students; adolescents prefer more quality of technical instructions from the coach which is not consistent with this study. According to Barrow (1997), junior athletes showed higher frequencies on the following training and instruction behavior which is consistent with this study.

Home town in which they are from is considered to identify the culture in which the athletes are from. Athletes who are from rural areas influence coaches to follow more training and instruction behavior than who are from urban. Further the urge for the coach to follow autocratic behaviors will be also more but not as significant as training and instruction behavior.

Terry (1984) found that no significant differences attributable to the nationality of an athlete. 
One of the most influential is that the experience that may hold by the athlete in relation to the specific sport.

According to the results when the experiences of the athletes are increasing, they influence coaches to practice more training and instruction, autocratic, social support positive feedback and situational consideration behavior respectively from the coaches.

Terry (1984) conducted the study with elite athletes where his findings can easily fit with path goal approach. The results said that elite athletes prefer more democratic behavior and social support behavior than club athletes. The results of the current study are consistent with the study done by Terry (1984) and path goal theory.

Please refer table 04. All the events considered in this study are team sports where some of the events prevail with high risk potentials. According to table 04 when the risk of getting injured is low, athletes perceive more training and instruction, feedback and situational behaviors from the coach. When the risk is high athletes perceive more feedback and situation consideration behavior from the coach.

As per table 4, when the competition among universities is high, the coaching preference of athletes varies among situational, positive feedback, democratic, training, social and autocratic behavior.

Therefore it can be concluded that the coaches carry out more situational consideration behavior and positive feedback behavior when the level of competition is high.

Another factor identified from the pilot survey is that the previous success records of the team. In relation to this study when the previous success records are high, the perception coaching preference of athletes vary from training, situational, positive feedback, democratic, social support and autocratic behavior.

According to table 4, previous success report of present coach is influential to the behaviors of the coach other than autocratic and social support behavior. The current study basically agrees with Barrow's (1977) findings on preference made for training and instruction.

Table 5. Overall mean values on coach leadership behavior

\begin{tabular}{|c|c|c|}
\hline $\begin{array}{c}\text { Team } \\
\text { member } \\
\text { characteristics }\end{array}$ & $\begin{array}{c}\text { Situational } \\
\text { characteristics }\end{array}$ & $\begin{array}{c}\text { Leadership } \\
\text { characteristics }\end{array}$ \\
\hline 3.22 & 3.49 & 3.53 \\
\hline
\end{tabular}

Source: Survey data, 2014

These three characteristics have moderate influence on coach leadership behavior. This is in line with the models developed by Smith and Smoll (1984) and Chelladurai and Carron (1978).

\section{CONCLUSIONS}

This generalization of results of coach's gender vs. coach leadership behavior is hindering in the current study since the results of only two female coaches were there to be analyzed. The mean values conclude that when the age level of the coach is increasing, the influence of the coach for training and instruction, and positive feedback leads to decrease.

Under the coach's locus of control vs. coach leadership behavior, athletes perceive more training and instruction behavior from coaches who believe on their skills. The present study revealed that the preference scores of the male athletes were considerably higher than those of female athletes for autocratic and training and instruction behavior only.

Accordingly when the age level increases athletes perceive more democratic behavior 
from coaches. At the same time when culture in which the team members are from is changing from urban to rural, the preference on coach behaviors by the athletes on democratic, social support, positive feedback and situational is reduced. The results of the study indicate that athletes of team sports considered here prefer more democratic behavior and situational consideration behavior, compared to other leadership behaviors.

Current study reveals that the athletes perceive more training and instruction, feedback and situational behaviors from the coach when the risk of getting injured is low. Further it is found that athletes perceive feedback, situational and democratic behavior when the risk of getting injured high.

Accordingly when the competition among universities is high, the coaching preferences of athletes are from situational, positive feedback, democratic, training, social and autocratic. Further to this study when the previous success records are high, the coaching preference of athletes are varying from training, situational, positive feedback, democratic, social support and autocratic.

\section{FUTURE WORK}

The same study can be extended to the Sri Lankan context since current study only focused on state universities in Western province. Not only the state universities but also the sports clubs, schools and related institutions can be taken into consideration for a better study.

The current study has limited the scope only to volleyball, basketball, hockey and elle. Further research can be carried out in the same manner on other team sports.

\section{REFERENCES}

BARROWJ. The variables of leadership. A review and conceptual framework. Acad Manage Rev. 1997;2, 231-51.
CARRON AV, CHELLADURAI P. Cohesion as a factor in sport performance. International Rev for the Sociology of Sport. 1981; 16, 21-41.

CENTRAL BANK OF SRI LANKA.CBSL. Annual report. Colombo. Sri Lanka. 2012.

CENTRAL BANK OF SRI LANKA. CBSL. Annual report. Colombo. Sri Lanka. 2013.

CHELLADURAI P, ARNOTT M. Dimension of leadership behavior in sports. Development of a leadership scale. J Sport Psychol. 1985 ; 5, 371-80

CHELLADURAI P, CARRON AV. Athlete maturity and preferred leadership.

J Sport Psychol, 1983; 5, 371-380

CHELLADURAI P \&CARRON AV. Leadership. Chapter, Sociology of Sport Monograph Series. Calgary, Alberta, Canada: University of Calgary. (1978)

CHELLADURAI P, SALEH S.D. Dimensions of leader behavior in sports: development of a leadership scale. J Sport Psychol, 1980; 2, 3445.

CHELLADURAI P. Leadership In Sports In: TENENBAUM G, EKLUND RC. Eds. Handbook Of Sport Psychology. Hoboken, New Jersey: John Wiley \& Sons, Inc. 2007; 113-35.

LIM B. Examining the organizational culture and organizational performance link. Leadership Org Dev J. 1995; 3, 16-21

MINISTRY OF FINACE \&PLANNING.MOFP. Colombo. Sri Lanka.2012.

NUNNALLY JC. Psychometric Theory. New York. McGraw-Hill. 1978.

PILUS AHM, SAADAN R. Coaching Leadership Styles and Athletes Satisfaction Among Hockey Team. J Hum Capital, 2009; 2, 77-87 
RIEMER HA, TOON KC. Leadership, Satisfaction in Tennis: Examination Of Congruence, Gender \& Ability. Res Q Exercise Sport. 2001; 72, 243-256

RINTAUGU EG, BAILASHA NK \& TORIOLA AL. Psycho-social attributes of elite African women volleyball players: sport psychology, Afr. J. Phys. Health Educ. Recr. Dance.2011; 17, 535-46.

RINTAUGU EG, BAILASHA NK. Negotiation constraint to Sport participation of university soccer players. J. EducPract. 2011; 23, 146-5.

ROTTER BJ.Generalized expectancies for internal verses external control of reinforcement. PsycholMonogr-Gen A. 1966; 128.

SMITH RE \& SMOLL FL. Coaching the coaches: Youth sports as a scientific and applied behavioral setting. Curr Dir Psychol Sci. 1997; 6, 16-21.

SMITH RE, SMOLL FL. Leadership behaviors in sport: A theoretical model and research paradigm. J ApplSoc Psychol. 1989; 19, 152251.

TERRY PC, HOWE B. Coaching Preferences of athletes. Can J Appl Sport Sci, 1984; 9,18893.

TERRY PC. The coaching preferences of Elite athletes competing at Universidad '83.Can J Appl Sport Sci. 1984; 9,201-8.

THE OLYMPIC MUSEUM. The Olympic Museum Educational Kit (HOPE). :IOC, The Olympic Museum, Lausanne, editors. Educational and Cultural Service Did We Dos. à.r.l; 2011.P.1-28.

ZHANG J, JENSEN BE \& MANN BL. Modification and revision of the leadership scale for sport. Journal of Sport Behavior, 1997; 20, 105-22. 